this was not news to me, although I have not yet reached the stage when I can, just because Prof. Armstrong says so, accept it as the complete and absolute faith.

It may be that I must both live and die a rebel. But $I$ do think it high time that someone might at least call a halt to this fifty years merciless (and to my mind, unfair) belabouring of the commercial man for the loss of a great and scientific industry; and it accords with poetic justice that this should be done by one who, if he cannot claim to be a chemist, cannot claim to be anything at all.

However, I am not unduly alarmed because Prof. Armstrong does agree with me that the pioneers did leave the industry, and that the industry did languish ; and, mark you, they were captains of their own industry - in those days "the commercial and management side" had not even arrived. Prof. Armstrong further tells us that when they, Perkin and Nicholson, retired, "the fate of the industry was sealed already in 1865". Why ? I can only gather from his letter that it was due to Perkin being "without imaginative power" and in the case of Nicholson because his partners "would not move with the times".

May I hope that when Prof. Armstrong reads a lecture which he did not hear, he may find that he is not in such complete disagreement "with the side represented by $\mathrm{Mr}$. Cronshaw-the managerial and commercial side" as a hasty pen led him to suppose.

I observe that Prof. Armstrong, obviously warming to his theme, says that "History cannot be written at a distance from the events by those who have had no direct knowledge of the period considered, and of the men concerned", a dictum that would have robbed the world of a large number of its greatest historians. It automatically robs chemistry of an attractive and provocative historian except for the space of four score years.

In his last paragraph, Prof. Armstrong has some hard words to say about the industry. I fear he has not the necessary feeling for the conditions prevailing. No one who is in a position to know shares his view, but this cannot be a novel situation for Prof. Armstrong. In one thing his letter completely persuades me: that it is possible to have "direct knowledge of the period considered and of the men concerned" and still not write history. However, for that we shall have to wait and see.

Dyestuffs Group,

Cecil J. T. Cronshaw.

Imperial Chemical Industries, Ltd. June 5 .

\section{Prediction of Earthquakes}

THE appalling havoc wrought by earthquakes in India during the past eighteen months has attracted. wide attention to the fact that, so far, science has failed completely to devise any means of providing a warning of the imminence of such disasters. At a lecture on Indian earthquakes, given at the Royal Society of Arts in March of last year ${ }^{1}$, this fact was deplored both by the lecturer, Sir Edwin Pascoe, and by Sir Thomas Holland, both of whom have held the position of director of the Geological Survey of India. In referring to the Bihar earthquake of January 1934, Sir Thomas Holland emphasised that "There was no warning whatever and that destruc. tion was sudden and complete in a few minutes". The same words apply equally well to the more recent disaster of Quetta and, in fact, to most major earthquake disturbances. The value of a warning, in the saving both of life and property, can scarcely be exaggerated; even if it is of a general character and comes long ahead of the actual disturbance.

As there are no reasons for supposing that this long-felt want will always lie beyond the powers of science, it is reasonable to suggest any line of approach which conceivably might lead to the desired end. One of these, which apparently has never been considered, lies in the possibility that anomalous electrical potentials may arise in the ground during the building up of the stress conditions which ultimately result in an earthquake. Electrokinetic phenomena may reasonably be looked for under such conditions, and if they could be detected and the resulting ground potentials proved to be measurable, then it is not unlikely that when mapped they would afford a clue as to the stress distribution in the district examined. In fact, to anyone with a fertile imagination and familiar with some of the recently developed methods in the electrical branches of applied geophysics, it seems just conceivable that the position of an epicentre might be predetermined in this way. Furthermore, the changes in the potential gradients with time might provide evidence as to the imminence of an earthquake disturbance.

A virtue which may be claimed for this tentative suggestion is that it is one which could be tested without great difficulty and, assuming that telegraph or other land lines could be used for the measurements, the expense would be relatively small. Periodical measurements of the potential differences existing between points on a network of stations in an area subject to seismic disturbance might well provide information of real value.

\section{London.}

A. B. Broughton Edge.

\section{June 4.}

1 J. Roy. Soc. Arts, 82, No. 4247, April 13, 1934.

\section{Critical Phenomena in the Oxidation and Self- Inflammation of Hydrocarbons}

Messrs. Neumann and Aivazov direct attention ${ }^{1}$ to the negative temperature coefficient of the combustion of hydrocarbon mixtures under certain conditions; this phenomenon, which has also been referred to by Pease ${ }^{2}$ and by Beatty and Edgar ${ }^{3}$, seems well established. The explanation given in the letter is a formal presentation of the views which have been put forward in various communications dealing with hydrocarbon combustion, the peroxide theory and knock in engines. The step $A \rightarrow B$ is the normal process whereby the hydrocarbon is oxidised to aldehyde.

The peroxide theory postulates that this process takes place via an intermediate peroxide which in normal circumstance may be written $\mathrm{RCH}_{3}+\mathrm{O}_{2} \stackrel{k_{1}}{\rightarrow}\left(\mathrm{RCH}_{3} \mathrm{O}_{2}\right) \stackrel{k_{2}}{\rightarrow} \mathrm{RCHO}+\mathrm{H}_{2} \mathrm{O}$, but in favourable circumstances the intermediate step can give rise to chain branching and hence eventually to ignition in a lower temperature range. The conditions for maximum concentration of $X$ or $\mathrm{RCH}_{3} \mathrm{O}_{2}$ are as indicated in Neumann and Aivazov's letter. The conditions in which chain branching occurs are particularly important in connexion with the phenomena of knock; thus the presence of antiknocks lower the effective concentration of $X$, while 